\title{
Diabetic peripheral neuropathy: the potential role of vitamin D deficiency
}

\author{
Mohammed I. Oraby ${ }^{1^{*}}$ (D), Mona Abu Srie ${ }^{1}$, Sanaa Abdelshafy ${ }^{2}$ and Eman Elfar ${ }^{3}$
}

\begin{abstract}
Background: Vitamin D is well known for its role in promoting calcium and phosphorus absorption and is recently associated with various neurological disorders.

Objective: To study the possible relation between vitamin D deficiency and diabetic peripheral neuropathy in a sample of patients recruited from Beni-Suef governorate, north Upper Egypt

Methods: A case-control study included 25 type 2 diabetic patients with diabetic peripheral neuropathy and 25 healthy controls. The patients included were subjected to clinical evaluation including Michigan Neuropathy Screening Instrument and nerve conduction study. And all patients and control were subjected to assessment of fasting and 2-h post prandial blood sugar, hemoglobin A1C, and serum vitamin D level.

Results: Serum vitamin D level was significantly lower in patients compared to control ( $P$ value $=0.008)$. For the patients group, females and patients with Michigan neuropathy screening instrument score more than 4 had statistically significant lower vitamin D level ( $P$ value $=0.003$ and 0.006 , respectively).

No statistically significant difference in vitamin $D$ level was found between patients below and above the age of 50 years, duration of diabetes less and more than 5 years, different types of diabetes medications, or patients with fair and poor control $(P$ value $=0.525,0.700,0.881$ and 0.252 , respectively). No significant correlation was found between vitamin $D$ level and the results of nerve conduction study.
\end{abstract}

Conclusion: Vitamin D deficiency was highly prevalent in diabetic peripheral neuropathy patients. Females and patients with severe form of neuropathy are more liable for lower vitamin D levels.

Keywords: Diabetic peripheral neuropathy, Vitamin D, MNSI, NCS

\section{Introduction}

The prevalence of diabetic peripheral neuropathy in newly diagnosed diabetic patients reaches about $8 \%$ and more than $50 \%$ in patients with long-standing disease [1]. Furthermore, about $15 \%$ of all diabetic patients will develop foot ulcer [2] and greater than 50\% of nontraumatic amputation of lower limbs is due to diabetes and its complications [3].

The pathogenesis of diabetic peripheral neuropathy is not understood completely. It is a multifactorial process and multiple hypotheses have been postulated, such as abnormal expression of sodium and calcium channels,

\footnotetext{
*Correspondence: Drm_Oraby@med.bsu.edu.eg; Drm_Oraby@hotmail.com All authors have read and approved the submitted manuscript; the manuscript has not been submitted nor published elsewhere in whole or in part.

${ }^{1}$ Department of Neurology, Beni-Suef University, Beni-Suef 62511, Egypt Full list of author information is available at the end of the article
}

metabolic and autoimmune disorders which lead to glial cell activation, blood vessel changes that affect the blood supply to the peripheral nerves and, recently, activation of central pain mechanisms as a result of imbalance between the facilitatory/inhibitory descending pathways [4].

In general, low vitamin D levels are associated with obesity and insulin resistance [5]. There is growing evidence that vitamin D plays an important role in the prevention of islet cell death and may be useful to improve the survival of islet cell grafts [6]. Low 25-hydroxyvitamin $\mathrm{D}$ levels have been associated with sensory neuropathy in diabetes and furthermore, vitamin D concentrations might be correlated with the severity of the neuropathy [7].

Studies in animal model of diabetes have demonstrated that treatment with vitamin D increases the level of nerve growth factor by stimulating its production and preventing its depletion. Nerve growth factor plays an 
important role in the development and survival of sensory and sympathetic neurons [8].

The aim of this study is to investigate the possible relation between vitamin $\mathrm{D}$ deficiency and diabetic peripheral neuropathy.

\section{Methods}

This study is a case-control study conducted in the Department of Neurology, Beni-Suef University Hospital and included 50 subjects: 25 type 2 diabetic patients with diabetic peripheral neuropathy (9 males and $16 \mathrm{fe}-$ males) and 25 age- and sex-matched healthy controls (9 males and 16 females).

Diabetic patients were diagnosed according to the American Diabetic Association criteria 2015 [9] when one of the following criteria is fulfilled: fasting plasma glucose $\geq 126 \mathrm{mg} / \mathrm{dL}$ ( $7.0 \mathrm{mmol} / \mathrm{L})$, fasting is defined as no caloric intake for $\geq 8 \mathrm{~h}$; 2 -h plasma glucose $\geq 200 \mathrm{mg} / \mathrm{dL}$ (11.1 $\mathrm{mmol} / \mathrm{L}$ ) during oral glucose tolerance test using a glucose load containing the equivalent of $75 \mathrm{~g}$ anhydrous glucose dissolved in water; hemoglobin $\mathrm{A} 1 \mathrm{C} \geq 6.5 \%(48 \mathrm{mmol} / \mathrm{l})$, or random plasma glucose $\geq 200 \mathrm{mg} / \mathrm{dL}(11.1 \mathrm{mmol} / \mathrm{L})$ in individuals with symptoms of hyperglycemia.

The presence of diabetic peripheral neuropathy was confirmed by Michigan Neuropathy Screening Instrument (MNSI) physical assessment [10]. All patients included in this study had a score of more than 2 .

Patients with the following conditions were excluded from this study: history of malignancy or degenerative disease of the nervous system, diabetic macrovascular complications, chronic hepatitis, pregnancy, and history of drug abuse, renal impairment with renal replacement therapy, and subjects on vitamin D supplementation.

A written informed consent was obtained from each participant in this study and the study was approved by the ethical committee of the Faculty of Medicine, Beni-Suef University (FWA00015574).

\section{All patients included in this study were subjected to the following \\ Clinical assessment}

Patients were submitted to clinical evaluation including detailed history taking focusing on the duration of diabetes mellitus, types of currently received treatment and symptoms of neuropathy, thorough neurological examination according to the neurology sheet currently used in the Neurology Department, Beni-Suef University, Michigan Neuropathy Screening Instrument Physical assessment; the Michigan Neuropathy Screening Instrument is designed to screen for the presence of diabetic neuropathy in an outpatient setting. It is a brief physical assessment that can be administered by any health care professional involved in the treatment of diabetic patients and includes inspection of the feet for deformities, dry skin, hair or nail abnormalities, callous or infection, semi-quantitative assessment of vibration sensation at the dorsum of the great toe, grading of ankle reflexes, and monofilament testing. Patients screening positive on the MNSI (greater than 2 points on a 10-point scale) are considered neuropathic with both a high specificity (95\%) and sensitivity (80\%) [10].

\section{Laboratory assessment}

Patients and control groups were subjected to the following laboratory investigations: fasting and 2 -h post prandial test and hemoglobin A1C test: level of HbA1C was classified into good control: $5.5-6.8 \%$, fair control: $6.8-7.6 \%$, and poor control: $>7.6 \%$ [11].

Serum vitamin D level was assessed in patients and control groups using Sat fax 303 Plus made in the USA to measure serum $25(\mathrm{OH})$ level. $25-\mathrm{OH}$ vitamin $\mathrm{D}$ is an ELISA-based test system intended for the quantitative measurement of total concentration of $25(\mathrm{OH})$-vitamin D in human serum or plasma samples (EDTA plasma, heparin plasma, citrate plasma) measuring $5-120 \mathrm{ng} / \mathrm{ml}$. Serum vitamin D level was classified into sufficiency: more than $30 \mathrm{ng} / \mathrm{ml}$, insufficiency: between 20 and $30 \mathrm{ng} / \mathrm{ml}$, and deficiency: below $20 \mathrm{ng} / \mathrm{ml}$ [12].

\section{Neurophysiological assessment}

Nerve conduction study was done for all patients with diabetic peripheral neuropathy using Nihon Kohden ${ }^{\circ}$ Neuropack machine, Japan. The test was explained to the patient who was seated on a long comfortable chair before the test proper sterilization of the skin with alcohol was done. The protocol used in this study was median and ulnar nerves (motor and sensory parts) in the upper limbs and peroneal nerve (motor part), tibial nerve (motor), and sural nerve (sensory part) in the lower limbs.

\section{Statistical analysis}

Data was coded, entered to Excel 2010 (Microsoft Corporation, NY, USA). Data was analyzed using SPSS version 24 (IBM Corp. Released 2016. IBM SPSS Statistics for Windows, Version 24.0. Armonk, NY: IBM Corp.). Number and percentages were used to summarize qualitative variables while mean and standard deviations were used for quantitative variables. Comparison between groups was done using chi-squares test (qualitative variables) and independent sample $t$ test (quantitative variables). Pearson correlation coefficient $(r)$ was used to test the correlation between quantitative variables. $P$ value less than or equal to 0.05 was considered as statistically significant.

\section{Results}

The age of diabetic peripheral neuropathy patients ranged from 29 to 73 years with a mean value of $54.6 \pm 12.12$ years, while the age of controls ranged from 27 to 67 years with a 
mean value of $49.76 \pm 11.93$ years. Both of patients and control groups had the same gender distribution (Table 1).

The clinical characteristics of diabetic peripheral neuropathy patients, duration and types of medical treatment of diabetes mellitus, level of glycosylated hemoglobin, MNSI score, and diabetic neuropathy syndromes (based on clinical examination and neurophysiological studies) were shown in Table 2.

All patients with diabetic peripheral neuropathy underwent nerve conduction study including parts of median and ulnar nerves (both sensory and motor), tibial, peroneal and sural nerves. The velocity, amplitude and latency were assessed in such nerves (Table 3).

The serum vitamin D level was evaluated for both control and diabetic peripheral neuropathy patient groups. The level in the patient group ranged from 11.1 to 39.2 with a mean value $19.216 \pm 7.59$. While the level in the control group ranged from 18.9 to 73.2 with a mean value $34.15 \pm 13.35$. The serum vitamin $\mathrm{D}$ level was significantly lower in diabetic peripheral neuropathy patients $P$ value $=0.008$ (Table 3). Different vitamin D level categories in diabetic peripheral neuropathy patients and control groups are shown in Table 4.

For the patient group, on comparing vitamin D levels in different demographic and clinical situations, females had significantly lower vitamin $\mathrm{D}$ level than males $(P$ value $=0.003)$ and diabetic peripheral neuropathy patients with Michigan neuropathy screening instrument score more than 4 had statistically significant lower vitamin D level compared to patients with Michigan neuropathy screening instrument score less than 4 ( $P$ value $=0.006$ ) (Table 5).

There was no statistically significant difference in the vitamin $\mathrm{D}$ level between patients below and above the age of 50 years, diabetic peripheral neuropathy patients with a duration of diabetes less and more than 5 years, diabetic patients receiving insulin, oral hypoglycemic drugs or combined insulin and oral hypoglycemic medications, and diabetes mellitus patients with fair and poor control $(P$ value $=0.525,0.700,0.881$ and 0.252 , respectively) (Table 5).

Correlation was carried between vitamin D level and the results of nerve conduction study. There was no statistically significant correlation between vitamin $\mathrm{D}$ and different values of the nerves included (Table 6).

Table 1 Demographic data of diabetic peripheral neuropathy patients and controls.

\begin{tabular}{|c|c|c|c|}
\hline & & Patients $(n=25)$ & Controls $(n=25)$ \\
\hline \multicolumn{2}{|c|}{ Age $($ mean $\pm S D)$} & $54.6 \pm 12.12$ & $49.76 \pm 11.93$ \\
\hline \multirow[t]{2}{*}{ Sex } & Male (number, \%) & $9(36 \%)$ & $9(36 \%)$ \\
\hline & Female (number, \%) & 16 (64\%) & $16(64 \%)$ \\
\hline
\end{tabular}

\section{Discussion}

Diabetic peripheral neuropathy is as a major cause for disability due to foot ulceration, gait disturbance, fall-related injuries, and even amputation. The prevalence of diabetic peripheral neuropathy is a function of disease duration; of all patients with diabetes, about 60 to $70 \%$ will eventually develop peripheral neuropathy, even though not all will suffer pain [13].

The aim of this work was to study the possible relation between vitamin $\mathrm{D}$ deficiency and diabetic peripheral neuropathy in a sample of patients recruited from Beni-Suef governorate, north Upper Egypt.

The study was conducted on 25 type 2 diabetic patients with diabetic peripheral neuropathy and 25 healthy controls. Sixty-four percent of the patients were found to have vitamin D deficiency, $28 \%$ were found to have vitamin D insufficiency, and only $8 \%$ of them were found to have normal serum vitamin $\mathrm{D}$ level.

Our findings are in accordance to the findings of Bayani and colleagues [14] who found vitamin D deficiency in $64.2 \%$ of their patients and vitamin D insufficiency in $25 \%$ and just $10.3 \%$ had normal vitamin $\mathrm{D}$ level.

A higher prevalence was found in a Korean study done by Lee and colleagues [15], $89 \%$ of their type 2 diabetic patients suffered vitamin D deficiency and only 9 out of 300 persons (3\%) had sufficient vitamin D concentration. They attributed high prevalence of vitamin D deficiency to the little duration of sunshine in Korea.

Also, compared to healthy controls from the same geographical area, matched in sex and age, patients with diabetic peripheral neuropathy have significantly lower serum vitamin D level.

Supporting our findings, many recent studies found that serum vitamin $D$ level in patients with diabetic peripheral neuropathy is significantly lower than that in healthy controls [16-18].

On the other hand, Tahrani and colleagues [19] and Usluogullari and colleagues [20] found no difference in the prevalence of vitamin $\mathrm{D}$ deficiency between diabetic peripheral neuropathy patients and controls. The contradiction between such results and our findings can be explained by, first, using different methods for diagnosis of peripheral neuropathy (they only used monofilament and vibration) and, second, neurophysiological tests had not been done.

Our study revealed that females with diabetic peripheral neuropathy had significantly lowered $25(\mathrm{OH})$ level than males. Similarly Lebanese and Japanese studies found that female patients with type 2 diabetes mellitus have had lower 25-OHD levels than male patients [21, 22]. In contrast, in an Iranian study, there was no significant difference between both genders in the vitamin D levels [23].

Gender difference in vitamin D level can be claimed to the interaction between circulating sex hormones and vitamin $\mathrm{D}$ concentrations. It is postulated that the observed 
Table 2 Clinical characteristics of diabetic peripheral neuropathy patients

\begin{tabular}{|c|c|c|}
\hline \multicolumn{2}{|l|}{ Clinical characteristics } & \multirow{2}{*}{$\begin{array}{l}\text { Patients (\%, number) } \\
56 \%(n=14)\end{array}$} \\
\hline Duration of diabetes mellitus & $\leq 5$ years & \\
\hline & $>5$ years & $44 \%(n=11)$ \\
\hline \multirow[t]{3}{*}{ Treatment of diabetes mellitus } & Insulin therapy & $52 \%(n=13)$ \\
\hline & Oral hypoglycemic drugs & $40 \%(n=10)$ \\
\hline & Combination of both & $8 \%(n=2)$ \\
\hline \multirow[t]{2}{*}{ Level of glycosylated hemoglobin } & Fair control (6.8-7.6) & $40 \%(n=10)$ \\
\hline & Poor control (> 7.6) & $60 \%(n=15)$ \\
\hline \multirow[t]{2}{*}{ MNSI score } & $\leq 4$ & $60 \%(n=15)$ \\
\hline & $>4$ & $40 \%(n=10)$ \\
\hline \multirow[t]{4}{*}{ Diabetic neuropathy syndromes } & Sensory neuropathy & $40 \%(n=10)$ \\
\hline & Sensorimotor neuropathy & $28 \%(n=7)$ \\
\hline & Radiculopathy & $16 \%(n=4)$ \\
\hline & Carpal tunnel syndrome & $16 \%(n=4)$ \\
\hline
\end{tabular}

effects of vitamin D are related to testosterone, which circulates at lower levels in females [24]. Also, pregnancy and lactation are potential causes for vitamin D deficiency [25]. Moreover, in the Arab world, while Arab males follow a western dress style, women usually dress in long clothes that cover a greater surface of the skin. Additionally, females have less outdoor activities as a result of cultural and religious habits [26].

Older adults have more liability for vitamin D deficiency as a result of many interacting factors: decreased the number of vitamin $\mathrm{D}$ receptor, intestinal resistance to calcium absorption in response to circulating $1,25(\mathrm{OH}) 2 \mathrm{D}$, decreased skin production of vitamin $\mathrm{D}$,

Table 3 Results of nerve conduction studies

\begin{tabular}{|c|c|c|c|c|c|c|}
\hline Nerve & & Minimum value & Maximum value & Mean \pm SD & Normal (number, \%) & Abnormal (number, \%) \\
\hline \multirow[t]{3}{*}{ Median (motor) } & Velocity & 39 & 72 & $50.14 \pm 8.48$ & $13(52 \%)$ & $12(48 \%)$ \\
\hline & Amplitude & 2.2 & 14.3 & $7.10 \pm 2.95$ & $21(84 \%)$ & $4(16 \%)$ \\
\hline & Latency & 3.5 & 9.4 & $5.18 \pm 1.59$ & $13(52 \%)$ & $12(48 \%)$ \\
\hline \multirow[t]{3}{*}{ Median (sensory) } & Velocity & 20 & 61 & $39.59 \pm 9.45$ & $2(8 \%)$ & $23(92 \%)$ \\
\hline & Amplitude & 0.11 & 39 & $17.84 \pm 11.37$ & 11 (44\%) & $14(56 \%)$ \\
\hline & Latency & 2.6 & 8 & $4.56 \pm 1.54$ & $5(20 \%)$ & $20(80 \%)$ \\
\hline \multirow[t]{3}{*}{ Ulnar (motor) } & Velocity & 38 & 70 & $52.25 \pm 7.29$ & $18(72 \%)$ & $7(28 \%)$ \\
\hline & Amplitude & 4 & 11.6 & $7.94 \pm 1.85$ & $21(84 \%)$ & $4(16 \%)$ \\
\hline & Latency & 2.5 & 7.3 & $4.05 \pm 1.43$ & $11(44 \%)$ & $14(56 \%)$ \\
\hline \multirow[t]{3}{*}{ Ulnar (sensory) } & Velocity & 32 & 60.4 & $48.39 \pm 7.72$ & $14(56 \%)$ & $11(44 \%)$ \\
\hline & Amplitude & 0.11 & 43.6 & $17 \pm 11.51$ & $10(40 \%)$ & $15(60 \%)$ \\
\hline & Latency & 1.8 & 4.1 & $2.80 \pm 0.56$ & 19 (76\%) & $6(24 \%)$ \\
\hline \multirow[t]{3}{*}{ Peroneal (motor) } & Velocity & 32 & 55 & $42.36 \pm 7$ & $11(44 \%)$ & $14(56 \%)$ \\
\hline & Amplitude & 0.3 & 7 & $3.08 \pm 1.69$ & 19 (76\%) & $6(24 \%)$ \\
\hline & Latency & 3.3 & 14.9 & $6.93 \pm 3.14$ & $14(56 \%)$ & $11(44 \%)$ \\
\hline \multirow[t]{3}{*}{ Tibial (motor) } & Velocity & 28 & 50 & $38.86 \pm 6.39$ & $9(36 \%)$ & $16(64 \%)$ \\
\hline & Amplitude & 1.5 & 15 & $6.21 \pm 3.50$ & 18 (72\%) & $7(28 \%)$ \\
\hline & Latency & 2.6 & 16 & $6.91 \pm 3.93$ & $15(60 \%)$ & $10(40 \%)$ \\
\hline \multirow[t]{3}{*}{ Sural (sensory) } & Velocity & 30 & 60 & $40.36 \pm 9.10$ & $11(44 \%)$ & $14(56 \%)$ \\
\hline & Amplitude & 0.1 & 18 & $6.34 \pm 4.95$ & $13(52 \%)$ & $12(48 \%)$ \\
\hline & Latency & 2.3 & 12 & $4.80 \pm 1.92$ & $12(48 \%)$ & $13(52 \%)$ \\
\hline
\end{tabular}


Table 4 Comparison between diabetic peripheral neuropathy patients and healthy controls regarding serum level of vitamin D

\begin{tabular}{|c|c|c|c|c|}
\hline & & Diabetic peripheral neuropathy patients & Control & $P$ value \\
\hline \multicolumn{2}{|c|}{ Serum level of vitamin D (Mean \pm SD) } & $19.216 \pm 7.59$ & $34.15 \pm 13.35$ & $0.008^{*}$ \\
\hline \multirow[t]{3}{*}{ Classification of vitamin D level } & Normal (number, \%) & $2(8 \%)$ & $13(52 \%)$ & $<0.001^{*}$ \\
\hline & Insufficiency (number, \%) & $7(28 \%)$ & $10(40 \%)$ & \\
\hline & Deficiency (number, \%) & $16(64 \%)$ & $2(8 \%)$ & \\
\hline
\end{tabular}

$P$ value $>0.05$ (nonsignificant)

*P value $<0.05$ (significant)

and the aging kidney produces lesser amounts of $1,25(\mathrm{OH}) 2 \mathrm{D}$ [27].

Our findings failed to detect a significant relation between age of patients and vitamin D. In concordance with our study, Suzuki and colleagues [22] found no significant correlation between the age of type $2 \mathrm{DM}$ patients and 25(OH)D level. Al-Timimi and Ali [28] found no significant difference between the serum $25(\mathrm{OH}) \mathrm{D}$ level of patients below the age of 40 and those above the age of 40 . In contrast, Leila and colleagues [23] and Kafshani and colleagues [29] found that serum vitamin D levels of type 2 diabetes patients were significantly correlated with their ages. In our study, there was a great variability in the disease duration and most of our patients had poor glycemic control, this may explain the insignificant relation between the age of patients and vitamin D level.

In this study, there was no significant relation between the level of HbA1c and serum vitamin D level. Similarly, Olt [30] and Usluogullari and colleagues [20] failed to detect a relationship between $\mathrm{HbA}_{1 \mathrm{c}}$ and serum 25-OH vitamin D levels and stated that $\mathrm{HbA1C}$ levels were similar across groups with different $25-\mathrm{OH}$ vitamin $\mathrm{D}$ concentrations.

Additionally, Al-Sofiani and colleagues [31] found that glycemic control did not differ between diabetic patients with vitamin $\mathrm{D}$ insufficiency or deficiency as compared to diabetic with normal vitamin $\mathrm{D}$ level. This means that the effect of vitamin $\mathrm{D}$ on diabetic neuropathy did not depend on the glycemic control.

In contrast, other studies demonstrated a negative correlation between $\mathrm{HbA} 1 \mathrm{C}$ and serum vitamin $\mathrm{D}$ level [22, 32].

It has been postulated that vitamin $\mathrm{D}$ deficiency may enhance diabetic nerve damage and may impair nociceptor function. As a result, diabetic patients will experience pain at a threshold of serum 25-OHD higher than that in the nondiabetic population [33].

For statistical purposes, we have divided our patients according to the score of Michigan neuropathy screening instrument physical examination into two groups (above and below 4); our results showed that diabetic

Table 5 Comparison between vitamin D levels in different demographic and clinical situations in diabetic peripheral neuropathy patients

\begin{tabular}{llll}
\hline & & $\begin{array}{l}\text { Vitamin D level } \\
\text { Mean } \pm \text { SD }\end{array}$ \\
\hline Sex & Male & $25.26(9.35)$ \\
& Female & $15.81(3.36)$ \\
Age & $<50$ years & $16.4(5.77)$ \\
& $\geq 50$ years & $20.31(8.06)$ \\
MNSI & $\leq 4$ & $22.44(8.046)$ \\
& $>4$ & $14.38(3.13)$ \\
Duration of DM & $\leq 5$ years & $19.75(6.8)$ \\
& $>5$ years & $18.53(8.79)$ \\
Type of DM treatment & Oral hypoglycemic drugs & $19.13(7.72)$ \\
& Insulin & $18.89(7.81)$ \\
& Combined oral hypoglycemic drugs and insulin & $21.9(9.89)$ \\
DM control & Fair control & $20.34(8.94)$ \\
& (HbA1C 6.9-7.6) & $18.46(6.78)$ \\
\hline
\end{tabular}

$P$ value $>0.05$ (nonsignificant)

MNSI Michigan Neuropathy Screening Instrument, DM diabetes mellitus

${ }^{*} P$ value $<0.05$ (significant) 
Table 6 Correlation between vitamin D and the results of nerve conduction study

\begin{tabular}{|c|c|c|c|}
\hline & & Serum vitamin & \\
\hline & & $(r)$ coefficient & $P$ value \\
\hline Median (M) & Velocity & -0.059 & 0.781 \\
\hline & Amplitude & -0.117 & 0.578 \\
\hline & Latency & 0.096 & 0.648 \\
\hline Median (S) & Velocity & 0.059 & 0.779 \\
\hline & Amplitude & 0.090 & 0.667 \\
\hline & Latency & -.0155 & 0.459 \\
\hline Ulnar (M) & Velocity & -0.093 & 0.658 \\
\hline & Amplitude & -0.040 & 0.848 \\
\hline & Latency & -0.110 & 0.602 \\
\hline Ulnar (S) & Velocity & -0.142 & 0.498 \\
\hline & Amplitude & -0.194 & 0.353 \\
\hline & Latency & -0.018 & 0.931 \\
\hline Peroneal (M) & Velocity & -0.084 & 0.688 \\
\hline & Amplitude & -0.079 & 0.706 \\
\hline & Latency & 0.273 & 0.187 \\
\hline Tibial (M) & Velocity & -0.044 & 0.833 \\
\hline & Amplitude & -0.022 & 0.916 \\
\hline & Latency & -0.311 & 0.130 \\
\hline Sural (S) & Velocity & -0.055 & 0.794 \\
\hline & Amplitude & -0.214 & 0.245 \\
\hline & Latency & 0.003 & 0.988 \\
\hline
\end{tabular}

$P$ value $>0.05$ (nonsignificant)

${ }^{*} P$ value $<0.05$ (significant)

peripheral neuropathy patients who scored more than 4 had a significantly lower serum vitamin D level.

Similarly, Shehab and colleagues [34] found that Neuropathy Disability Score showed significant positive correlation with vitamin D. Also, Basit and colleagues [35] who studied 143 participants known to be type 2 diabetes with diabetic neuropathy and assessed neuropathic pain using Douleur Neuropathique 4 (DN4) score, total McGill pain score, and Short Form McGill Pain Questionnaire (SFMPQ) score. 40.5\% patients showed evidence of vitamin D deficiency. A single intramuscular dose of 600,000 IU vitamin $\mathrm{D}$ resulted in a significant increase in vitamin $\mathrm{D}$ level and a reduction in positive symptoms on the DN4, total pain score, and SFMPQ.

In contrast, Chyachi and colleagues [7] found no significant association between the level of 25-hydroxyvitamin D and the severity of diabetic neuropathy. Different findings could be attributed to using different scores in the assessment of the severity of diabetic peripheral neuropathy.

A long duration of diabetes and poor glycemic control potentiate metabolic derangements, the production of glycosylation end products, oxidative stress, and endothelial injury [36]. For statistical purposes, we have divided our patients according to duration of diabetes mellitus into two groups: diabetic peripheral neuropathy patients with disease duration less than 5 years and more than 5 years. There was no significant difference between both groups regarding serum vitamin $\mathrm{D}$ level.

Similarly, the study done by Al-Agha and Ahmad [37] in Saudi Arabia revealed insignificant difference between different serum vitamin D levels regarding disease duration (more and less than 5 years). In contrast, Al-Timimi and Ali [28] studied serum 25(OH) D in 337 Kurd patients with DM type 2 and found that serum $25(\mathrm{OH})$ D levels was statistically lower in patients with a diabetes duration more than 5 years compared to duration less than 5 years.

The discrepancy in the results could be explained by the different cutoff points used to classify patients as on sufficient vitamin D status, the difference in the sample size of the patients. Also, in our study, most of the time, there is uncertain delay between the occurrence of the disease and its discovery (low socioeconomic level and limited health resources).

Vitamin D deficiency has a negative effect on beta cell function, decreases insulin sensitivity, and increases insulin resistance [38].

In the present study, serum vitamin D level is not related to whether the patients are currently receiving insulin, oral hypoglycemic drugs, or combined therapy. Similarly, Kos and colleagues [39] in their study which includes 706 type 2 diabetic patients with a wide range of age (20 to 93 years) found no statistically significant difference between users and nonusers of metformin as an oral hypoglycemic agent regarding serum vitamin D level.

Many studies found that $25(\mathrm{OH})$ vitamin $\mathrm{D}$ levels of the insulin-taking patients were lower than that of the oral hypoglycemic drug-taking patients and control group. And that DM patients treated with insulin had the highest DPN prevalence [40-42].

These findings could be explained by the failure of diet and various oral hypoglycemic agents singly or in combination before starting insulin therapy. So, such patients could have several periods of poor glycemic control before the therapy was intensified [14].

In our study, NCS including median nerve (motor and sensory), ulnar nerve (motor and sensory), tibial nerve (motor), peroneal nerve (motor), and sural nerve (sensory) was done to all patients and revealed no significant relation to different serum vitamin D levels.

Similarly, in Shehab and colleagues' [34] study, motor nerves include peroneal, tibial, median, and ulnar nerves and the sensory nerves include sural, median, and ulnar nerves. None of the nerve conduction scores showed significant association with vitamin D status.

Additionally, another study included 112 type 2 diabetic patients with diabetic peripheral neuropathy divided to a treatment group with vitamin D and a placebo group. No 
difference was observed for Neuropathy Disability Score and nerve conduction study between the two groups after treatment [43].

The pathophysiology of the peripheral neuropathy in diabetes is complicated and other causes such as poor glycemic control and metabolic syndrome are involved. This can explain the absence of direct correlation between vitamin $\mathrm{D}$ level and the results of nerve conduction studies.

\section{Conclusion}

Vitamin D deficiency was highly prevalent in diabetic peripheral neuropathy patients compared to controls. Attention should be paid to the link between vitamin D level and diabetic peripheral neuropathy and whether routine testing of serum vitamin $\mathrm{D}$ level in all diabetes mellitus patients should be done.

The limitation of this work is the relatively small number of patients due to the limitation of resources and financial issues.

Further studies should be conducted on a larger number of patients and for a longer duration to explore whether supplementation with vitamin D could prevent the development or improve the manifestations of peripheral neuropathy in diabetic subjects.

\section{Abbreviations}

25(OH) D: 25-Hydroxyvitamin D; DM: Diabetes mellitus; DN4: Douleur Neuropathique 4; HbA1C: Hemoglobin A1C; MNSI: Michigan Neuropathy Screening Instrument; NSC: Nerve Conduction Study; SFMPQ: Short Form McGill Pain Questionnaire

\section{Acknowledgements}

Not applicable.

\section{Funding}

Authors did not receive any funding for this work.

\section{Availability of data and materials}

This paper is a part of a thesis conducted in Faculty of Medicine, Beni-Suef University, Egypt and approved by its research and ethical committees. The datasets used and/ or analyzed during the current study are available from the corresponding author on reasonable request with permission of Faculty of Medicine, Beni-Suef University, Egypt.

\section{Authors' contributions}

$\mathrm{MO}$ participated in the study design, sequence alignment, and analysis of the data and helped to draft the manuscript. MA participated in the study design, sequence alignment, and collection of the data and helped to draft manuscript. SA performed the laboratory work and helped to draft the manuscript. EE participated in the study design and analysis of the data and helped to draft the manuscript. All authors read and approved the final manuscript.

\section{Ethics approval and consent to participate}

A written informed consent was obtained from each participant in this study and the study was approved by the authorized ethical committee in Faculty of medicine, Beni-Suef University (FWA00015574) in 3-7-2018.

\section{Consent for publication}

Not applicable.

\section{Competing interests}

The authors declare that they have no competing interests.

\section{Publisher's Note}

Springer Nature remains neutral with regard to jurisdictional claims in published maps and institutional affiliations.

\section{Author details}

'Department of Neurology, Beni-Suef University, Beni-Suef 62511, Egypt. ${ }^{2}$ Department of Clinical Pathology, Beni-Suef University, Beni-Suef, Egypt. ${ }^{3}$ Public Health and Community medicine Department, Cairo University, Giza, Egypt.

Received: 2 October 2018 Accepted: 13 January 2019

Published online: 25 January 2019

\section{References}

1. Boulton A, Malik R, Arezzo J, Sosenko J. Diabetic somatic neuropathies (technical review). Diabetes Care. 2004;27:1458-86.

2. Thomas P. Diabetic peripheral neuropathies: their cost to patient and society and the value of knowledge of risk factors for development of interventions. Eur Neurol. 1999:41(Suppl 1):35-43.

3. Dang C, Boulton A. Changing perspectives in diabetic foot ulcer management. Int J Low Extrem Wounds Mar. 2003;2(1):4-12.

4. Tesfaye S, Boulton A, Dyck P, Freeman R, Horowitz M, Kempler P, et al. Diabetic neuropathies: update on definitions, diagnostic criteria, estimation of severity, and treatments. Diabetes Care. 2010;33:2285-93.

5. Hahn S, Haselhorst U, Tan S, Quadbeck B, Schmidt M, Roesler S, et al. Low serum 25-hydroxyvitamin $D$ concentrations are associated with insulin resistance and obesity in women with polycystic ovary syndrome. Exp Clin Endocrinol Diabetes. 2006;114(10):577-83.

6. Riachy R, Vandewalle B, Moerman E, Belaich S, Lukowiak B, Gmyr V, et al. 1,25-Dihydroxyvitamin D3 protects human pancreatic islets against cytokine-induced apoptosis via down-regulation of the Fas receptor. Apoptosis. 2006;11(2):151-9.

7. Chaychi L, Mackenzie T, Bilotta D, Lynch M, Cohen J, Comi R. Association of serum vitamin D level with diabetic polyneuropathy. Medical Practice and Review. 2011;2(1):11-5.

8. Riaz S, Tomlinson D. Pharmacological modulation of nerve growth factor synthesis: a mechanistic comparison of vitamin D receptor and beta(2)adrenoceptor agonists. Brain Res Mol. 2000;85:179-88.

9. American Diabetes Association. Diagnosis and classification of diabetes mellitus. Diabetes Care. 2015;38(Supplement 1):S8-S16. https//doi.org/10.2337/dc15-S005.

10. Feldman EL, Stevens MJ, Thomas PK, et al. A practical two-step quantitative clinical and electrophysiological assessment for the diagnosis and staging of diabetic neuropathy. Diabetes Care. 1994;17:1281.

11. Sachin A. A study of plasma fibrinogen level in type-2 diabetes mellitus and its relation to glycemic control. Indian J Hematol Blood Transfus. 2012;28(2):105-8.

12. Lips P. Vitamin D physiology. Prog Biophys Mol Biol. 2006;92:4-8.

13. Juster-Switlyk K and Smith AG. Updates in diabetic peripheral neuropathy. F1000Research. 2016; 5:F1000 Faculty Rev-738. doi:https://doi.org/10.12688/ f1000research.7898.1.

14. Bayani M, Akbari R, Banasaz B, Saeedi F. (2014): Status of vitamin-D in diabetic patients. Caspian Journal of Internal Medicine. 2014;5(1):40-2.

15. Lee J, Oh S, Ha W, Kwon H, Sohn T, Son H, Cha B. Serum 25-hydroxyvitamin $\mathrm{D}$ concentration and arterial stiffness among type 2 diabetes. Diabetes Res Clin Pract. 2012;95(1):42-7.

16. Sarita B, Raj P, Dwivedi N, Kamaljeet S, Arvind G, Manoj M. Vitamin D levels and microvascular complications in type 2 diabetes. Indian J Endocrinol Metab. 2014;18(4):537-41.

17. Asuman C, Ayse G, Nermin T, Elif B, Mehmet A, Mehmet C, et al. Decreased serum vitamin $D$ levels are associated with diabetic peripheral neuropathy in a rural area of Turkey. Acta Neurol Belg. 2015;115:47-52.

18. Bulent B, Feti $T$, Betul E, Sonat $P$, Tulay $Y$, Seyit A, et al. The association of vitamin $D$ with inflammatory cytokines in diabetic peripheral neuropathy. J Phys Ther Sci. 2016;28:2159-63.

19. Tahrani A, Ball A, Shepherd L, Rahim A, Jones A, Bates A. The prevalence of vitamin $D$ abnormalities in South Asians with type 2 diabetes mellitus in the UK. Int J Clin Pract. 2010;64:351-5.

20. Usluogullari C, Balkan F, Caner S, Ucler R, Kaya C, Ersoy R, et al. The relationship between microvascular complications and vitamin $D$ deficiency 
in type 2 diabetes mellitus. BMC Endocrine Disorders. 2015;25:15-33. https://doi.org/10.1186/s12902-015-0029-y.

21. Ahmadieh H, Azar S, Lakkis N, Arabi A. Hypovitaminosis D in patients with type 2 diabetes mellitus: a relation to disease control and complications. ISRN Endocrinol. 2013;2013:641098. https://doi.org/10.1155/2013/641098.

22. Suzuki A, Kotake M, Ono Y, Kato T, Oda N, Hayakawa N, Hashimoto S, Itoh M. Hypovitaminosis D in type 2 diabetes mellitus: association with microvascular complications and type of treatment. Endocr J. 2006;53(4):503-10.

23. Leila M, Reza M, Sadoughi M, Beigrezaei S. Vitamin D status and its relationship with age in type 2 diabetic patients. Journal of Parathyroid Disease. 2017:5(2):45-8

24. Seeman E. Unresolved issues in osteoporosis in men. Rev Endocr Metab Disord. 2001;2:45-64.

25. Langlois K, Greene-Finestone L, Little J, Hidiroglou N, Whiting S. Vitamin D status of Canadians as measured in the 2007 to 2009 Canadian Health Measures Survey. Health Rep. 2010;21:47-55.

26. Saliba W, Rennert H, Kershenbaum RG. Serum $25(\mathrm{OH}) \mathrm{D}$ concentrations in sunny Israel. Osteoporos Int. 2012;23(2):687-94

27. Gallagher J. Vitamin D and aging. Endocrinol Metab Clin N Am. 2013;42(2):319-32.

28. Al-Timimi $\mathrm{D}$, Ali A. Serum $25(\mathrm{OH}) \mathrm{D}$ in diabetes mellitus type 2: relation to glycaemic control. J Clin Diagn Res. 2013;7(12):2686-8.

29. Kafeshani M, Zarafshani M, Shokri-Moghaddam S, Ahmadi A, Nasri H. Serum 25-hydroxy vitamin $\mathrm{D}$ level in diabetic patients versus normal individuals; a pilot study. J Parathyr Dis. 2016;42:41.

30. Olt $\mathrm{S}$. Relationship between vitamin $\mathrm{D}$ and glycemic control in patients with type 2 diabetes mellitus. Int J Clin Exp Med. 2015:8(10):19180-3.

31. Al-Sofiani ME, Jammah A, Racz M, Khawaja RA, Hasanato R, et al. Effect of vitamin $\mathrm{D}$ supplementation on glucose control and inflammatory response in type II diabetes: a double blind, randomized clinical trial. Int J Endocrinol Metab. 2015;13(1):e22604. https://doi.org/10.5812/ijem.22604.

32. Buhary B, Almohareb O, Aljohani N, Alrajhi S, Elkaissi S, Sherbeeni S, et al. Association of glycosylated hemoglobin levels with vitamin D status. J Clin Med Res. 2017:9(12):1013-8.

33. Naveilhan P, Neveu I, Wion D, Brachet P. 1,25-Dihydroxyvitamin D3, an inducer of glial cell line-derived neurotrophic factor. Neuroreport. 1996;7:2171-5.

34. Shehab D, Al-Jarallah K, Mojiminiyi O, Al Mohamedy H, Abdella N. Does vitamin $D$ deficiency play a role in peripheral neuropathy in type 2 diabetes? Diabet Med. 2012;29(1):43-9.

35. Basit A, Basit K, Fawwad A, Shaheen F, Fatima N, Petropoulos I, et al. Vitamin $\mathrm{D}$ for the treatment of painful diabetic neuropathy. BMJ Open Diabetes Research \& Care. 2016;4(1):e000148.

36. Nishikawa T, Edelstein D, Du XL, Yamagishi S, Matsumura T, Kaneda Y, et al. Normalizing mitochondrial superoxide production blocks three pathways of hyperglycaemic damage nature. 2000;404(6779):787-90.

37. Al-Agha A, Ahmad I. Association among vitamin D deficiency, type 1 diabetes mellitus and glycemic control. J Diabetes Metab. 2015;6:594. https://doi.org/10.4172/2155-6156.1000594.

38. Chiu K, Chu A, Go V, Saad M. Hypovitaminosis D is associated with insulin resistance and beta cell dysfunction. Am J Clin Nutr. 2004;79(5):820-5.

39. Kos E, Liszek Mu, Emanuele MA, Durazo-Anvizu R, Camacho P. Effect of metformin therapy on vitamin $D$ and vitamin $B_{12}$ levels in patients with type 2 diabetes mellitus. Endocr Pract. 2012;18(2):179-84. https//doi.org/10.4158/EP11009.OR.

40. Franklin G, Shetterly S, Cohen J, Baxter J, Hamman R. Risk factors for distal symmetric neuropathy in NIDDM. The San Luis Valley diabetes study. Diabetes Care. 1994;17(10):1172-7.

41. Pop-Busui R, Lu J, Lopes N, Jones T, BARI 2D investigators. Prevalence of diabetic peripheral neuropathy and relation to glycemic control therapies at baseline in the BARI 2D cohort. J Peripher Nerv Syst. 2009;14(1):1-13.

42. Boyraz I, Bilge U, Ünalacak M, Bilgin M. The comparison of $25(\mathrm{OH})$ vitamin D level in type 2 diabetes patients taking oral anti-diabetics and insulin. Biomed Res. 2016:27(1):24-8.

43. Shehab D, Al-Jarallah K, Abdella N, Mojiminiyi O, Al MH. Prospective evaluation of the effect of short-term oral vitamin $D$ supplementation on peripheral neuropathy in type 2 diabetes mellitus. Med Princ Pract. 2015;24(3):250-6. 